\title{
Subjective evaluation of Japanese voiceless affricate spoken by Korean
}

\author{
Kimiko Yamakawa ${ }^{1, *}$, Yoshifumi Chisaki ${ }^{2}$ and Tsuyoshi Usagawa ${ }^{2}$ \\ ${ }^{1}$ Graduate School of Science and Technology, Kumamoto University, \\ 2-39-1 Kurokami, Kumamoto, 860-8555 Japan \\ ${ }^{2}$ Department of Computer Science, Faculty of Engineering, Kumamoto University, \\ 2-39-1 Kurokami, Kumamoto, 860-8555 Japan
}

(Received 16 November 2005, Accepted for publication 17 February 2006)

Keywords: Voiceless alveolar affricate, Sound of $t s u$ in Japanese, Learning term, Korean native speaker, Japanese learner PACS number: 43.70.Es, 43.71.Hw [doi:10.1250/ast.27.236]

\section{Introduction}

The difficulty involved in the pronunciation of the voiceless alveolar affricate $t s u$ in Japanese language is often pointed out by teachers and learners of Japanese. The learners of Japanese as a second language (L2) whose native language (L1) is Korean tend to utter $\operatorname{chu}([\mathrm{f} \mathrm{w}])$ for /tsu/ e.g., atsui (which means "hot") to achui, hitotsu (a single piece) to hitochu, and L2 learners of Japanese whose L1 is English tend to utter $t s u$ as su, e.g., tsukue (desk) to sukue [1,2]. These errors of pronunciation are likely to cause misunderstanding during communication because of ambiguity in the intended meaning. For example, the pronunciation chu like hitochu is used in baby talk in Japanese. There can also be confusion in the intended meaning when $t s u$ and $s u$ are interchanged. In order to discover effective teaching methods to help learners acquire the affricate $t s u$ in Japanese, this paper intends to analyse the tendency of pronunciation of the affricate $t s u$ spoken by L2 learners, especially Korean, by means of evaluation testing. A discussion of this tendency is also presented with the results of the spectrogram analysis.

\section{Japanese and Korean affricates}

$T s u$ is a voiceless alveolar affricate in Japanese. An affricate is a consonant that begins with an oral stop (most often $[\mathrm{t}$ ] or $[\mathrm{d}]$ ) but ends with a fricative release. Table 1 shows the comparison between Japanese and Korean affricates. Japanese has two voiceless affricates: [ts, tc], and two voiced affricates: [c, d ] . Usually, [ts] involves a high back vowel /u/ in Japanese. The standard Korean usually includes three voiceless affricates, $[\mathrm{t}],\left[\mathrm{t}^{\mathrm{h}}\right]$ and $\left[\mathrm{t}^{\prime}\right][3,4]$. The symbol ['] represents a tense phoneme. Tense or lax distinction is said to relate to the degree or pressure of glottal constriction during production. Three Korean affricate phonemes are categorized as lax, aspirate, and tense in production.

\section{Method}

An evaluation test was conducted to study how received native Japanese sounds uttered by Korean learners were perceived.

\subsection{Participants}

The selected speakers were 13 native speakers of Korean

*e-mail: jin@hicc.cs.kumamoto-u.ac.jp who had studied Japanese for 3 to 36 months and who had stayed in Japan less than half a year. They were divided into two groups, KS and KL. Group KS had seven Korean learners who had studied Japanese for less than 150 hours and group KL had six Korean learners who had studied for 300 hours or more. Group KS had a beginner's level of Japanese while group KL had of an intermediate level. The utterance of one native speaker of Japanese (JN) is used for comparison with the results of the Koreans' utterances.

\subsection{Stimuli}

The speech material consisted of nine Consonant-Vowel (CV) syllables. $\mathrm{C}$ was affricate [ts, $\left.\mathrm{t}_{6}\right]$ or fricative [s], and $\mathrm{V}$ was [u]. The front and back of CVs had the same phonetic environment [ma] to be located at word-initial, word-medial or word-final. These words were used in isolation; that is, they were not embedded in sentences, to limit possible variables such as phrases preceding and following target stimuli that may influence the evaluation of those words by evaluators. Details of the words are shown in Table 2.

All nine words have the same accent patterns (only the first mora is high and the rest of the morae have a low pitch).

In these stimuli, tsuma, suma and matsu were real words in Japanese.

$$
\begin{aligned}
& \text { tsuma } \text { [tsuma] } \\
& \text { suma } \text { [suma] } \\
& \text { matsu } \text { [matsu] } \\
& \text { pine, wame }
\end{aligned}
$$

However, these three words will not be familiar to nonnative Japanese speakers, particularly for subjects who have been in Japan a shorttime. These stimuli were uttered three times by 14 speakers, and the 2 nd and 3rd sounds were used for this test. These sounds were recorded on a digital audiotape at $44.1 \mathrm{kHz}$ with 16-bit resolution.

\subsection{Procedure}

In this test, a total of 252 sounds, nine types of sound pronounced by the 13 Korean learners and one native speaker of Japanese, were used and these stimuli were randomly grouped into six sets. The stimuli were presented to evaluators at a comfortable listening level through headphones in a quiet room. The evaluators were nine native speakers of Japanese who had never lived in any foreign country and had never communicated with non-native speakers of Japanese (except for one evaluator). This test was conducted by dictating by 
Table 1 Comparison between Japanese and Korean affricates.

\begin{tabular}{|c|c|c|c|c|c|}
\hline & \multicolumn{2}{|c|}{ Japanese } & \multicolumn{3}{|c|}{ Korean } \\
\hline & Voiceless & Voiced & Lax & Aspirate & Tense \\
\hline Alveolar & ts & d & - & - & - \\
\hline Postalveolar & - & - & t & $\mathrm{tg}^{\mathrm{h}}$ & tf \\
\hline Alveolo-palatal & t6 & \& & - & - & - \\
\hline
\end{tabular}

Table 2 Speech materials used in evaluation test.

\begin{tabular}{|c|c|c|c|}
\hline & word-initial & word-medial & word-final \\
\hline $\begin{array}{c}\text { Affricate } \\
{[\mathrm{ts}]}\end{array}$ & $\begin{array}{c}\text { tsuma } \\
\text { [tsuma] }\end{array}$ & $\begin{array}{c}\text { matsuma } \\
\text { [matsuma] }\end{array}$ & $\begin{array}{c}\text { matsu } \\
\text { [matsu] }\end{array}$ \\
\hline $\begin{array}{c}\text { Affricate } \\
{\left[\mathrm{t}_{6}\right]}\end{array}$ & $\begin{array}{c}\text { chuma } \\
\text { [tcuma] }\end{array}$ & $\begin{array}{c}\text { machuma } \\
\text { [matcuma] }\end{array}$ & $\begin{array}{c}\text { machu } \\
\text { [tcuma] }\end{array}$ \\
\hline $\begin{array}{c}\text { Fricative } \\
{[\mathrm{s}]}\end{array}$ & $\begin{array}{c}\text { suma } \\
\text { [suma] }\end{array}$ & $\begin{array}{c}\text { masuma } \\
\text { [masuma] }\end{array}$ & $\begin{array}{c}\text { masu } \\
{[\text { masu] }}\end{array}$ \\
\hline
\end{tabular}

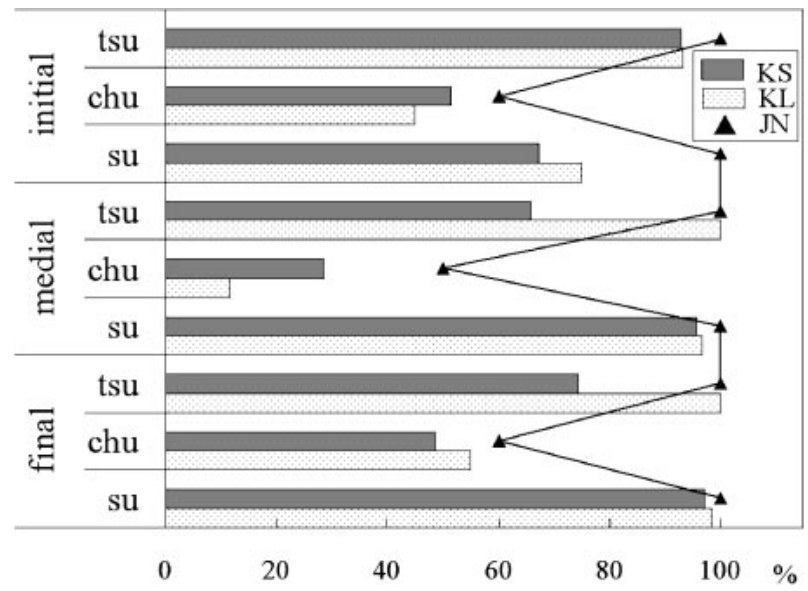

Fig. 1 Pronunciation accuracy by Korean learners (KS, $\mathrm{KL})$ and one native speaker of Japanese (JN). The vertical axis shows the stimuli, and the horizontal axis shows the degree of accuracy.

hiragana (one of the two sets of symbols of Japanese syllabic writing, which presents phonemes). The time allowed for dictation was three seconds per sound. The results of the evaluation test measured the accuracy of the pronunciation, in percentage, where pronunciation was counted as "correct" when the evaluation by the native Japanese agreed with the intent of the speaker.

\section{Results}

Figure 1 shows the evaluation of the Korean learner's pronunciation as measured by the accuracy of each stimuli's perception by the native Japanese. In this figure, the results obtained from the utterances by the two groups of Korean speakers, KS and KL, are shown as well as those obtained from utterances by the native Japanese as the solid line with filled triangles. The ANOVA algorithm was then applied to

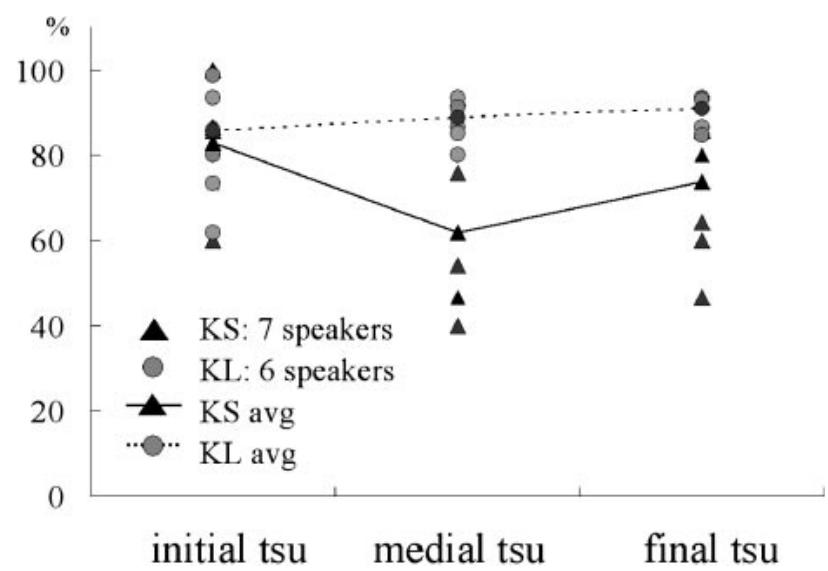

Fig. 2 Accuracy of $t s u$. The vertical axis shows the degree of accuracy, and the horizontal axis shows the stimuli.

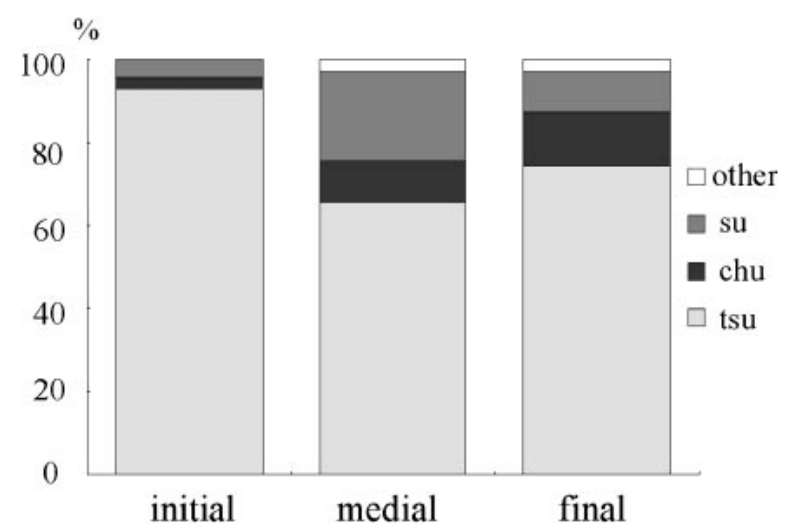

Fig. 3 Result of evaluation for $t s u$. The vertical axis shows the percentage of evaluation and the horizontal axis shows the position of $t s u$.

the results. Statistically significant nteractions among stimuli ( $t s u, c h u$ and $s u$ ) were found concerning the accuracy of utterance $\left(F_{(2,22)}=45.10, p<.01\right)$. This means that speech accuracy is influenced by the length of study. Regarding group KS, statistically significant interactions among stimuli positions (initial, medial and final) were found in the accuracy of speech $\left(F_{(2,22)}=4.83, p<.05\right)$. It was found that the medial and final $t s u$ 's are difficult to pronounce for group KS.

Figure 2 shows the results of the accuracy of $t s u$ corresponding to each speaker. As shown in this figure, the accuracy of medial and final tsu's varies widely among the subjects in group KS, where these tsu's were perceived as /chu/ or /su/ by Japanese native speakers. The result of evaluation for $t s u$ of each position is shown in Fig. 3. It was found that word-medial and word-final $t s u$ were perceived as /chu/ or /su/ by Japanese native speakers.

\section{Discussion}

The result of the evaluation test shown in Figs. 1 and 2 shows that the $t s u$ spoken by Korean learners of Japanese is perceived as $c h u$ by native Japanese. As for the pronunciation accuracy of $c h u$, however, it was lower than the other sounds 


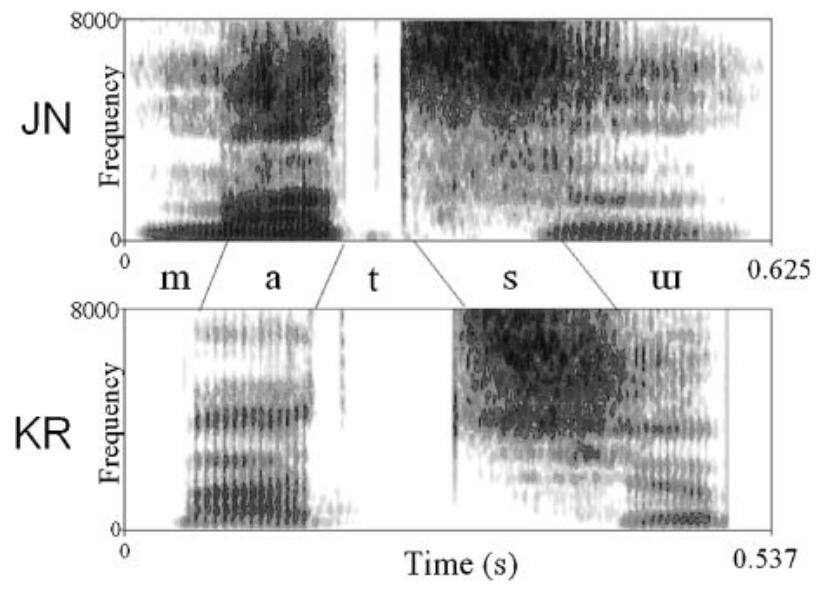

Fig. 4 Spectrograms of matsu pronounced by JN and KR.

and was perceived as $t s u$ by native Japanese. In relation to this issue, the evaluation results of native Japanese pronunciation helps to account for it. As shown in Fig. 1, it can be observed that $c h u$ pronounced by the Japanese native speaker (JN) was judged as $t s u$ by the Japanese evaluators, too. In Japanese, [t6] is usually pronounced as chuu [t6w:] with a long vowel [w:], e.g., chuugaku [tcw:gakw] (junior high school), uchuu [utcur] (space). Thus, it appears that the native Japanese felt a sense of unease with chuma, machuma and machu without the long vowel [u:] after [tc]. This is just another way of saying that native Japanese are intolerant of [tc] without a long vowel [u:]. In this case, $c h u$ may be perceived more than just an error by native Japanese if Korean learners pronounced chu instead of $t s u$. About this issue, there is a limitation to this study. Some words used in this study may be familiar to native Japanese speaking evaluators. To obtain minimal pair words with the same phonetic environment, however, the word set used here is a realistic selection under the limited conditions for speakers. Again, various experiments need to be conducted to overcome technical constraints. Figure 4 shows the spectrograms of matsu pronounced by a Korean learner of Japanese (KR) and a native speaker of Japanese (JN). Matsu by KR was perceived as machu by all evaluators. Matsu by KR differs from JN in terms of the energy distributions of the fricative part in affricate [ts]. The fricative part of KR has a higher spectral level in the low-frequency range than that of JN. The difference in the phonetic value of the fricative part is understood as one of the factors for perception of $t s u$ as $c h u$.

\section{Conclusions}

This study was conducted to examine the pronunciation of affricate $t s u$ in Japanese uttered by Korean learners of Japanese. Results show that $t s u$ as medial and final morae uttered by Korean learners are perceived as chu or su by native speakers of Japanese. According to the spectral comparison, it can be considered that the phonetic value of the fricative part of $t s u$ pronounced by Koreans differs from $t s u$ pronounced by Japanese.

Native speakers of Japanese have little tolerance for chu without a long vowel $/ \mathrm{u} /$. Although this is a problem caused by mispronouncing only one phoneme, it is an important problem to solve for smooth communication. Further studies are required to understand the cause of pronunciation errors. We need to consider the preceding vowel and the voicedvoiceless contrast.

\section{References}

[1] Y. Sukegawa, "The tendency of the pronunciation according to the native language -from the result of a questionnaire," Jpn. Phonet. Jpn. Educ. (D1 research achievement report of MEXT, Tokyo), pp. 187-222 (1993).

[2] H. Matsuzaki, "Phonetic Education of Japanese for Korean Speakers," J. Phonet. Soc. Jpn., 3, 26-35 (1999).

[3] Y. Yamada, "The measurement of the difficulty level for Japanese cognition in Korean," J. Jpn. Lang. Teach., 3, 19-33 (1963).

[4] A. M. Schmidt and K. A. Meyers, "Traditional and phonological treatment for teaching English fricatives and affricates to Koreans," J. Speech Hear. Res., 38, 828-838 (1995). 